\title{
Family Therapy and Young Abusers
}

\section{Experiences from the multi-agency treatment service TVERS in Vest-Agder County, Norway}

Authors:

1. Siri Søftestad, Reseacher and Ph.D.student, Sørlandet Hospital, Child and Adolescent Psychiatry, Kristiansand, Norway. siri.softestad@sshf.no

2. Margareth Bjørtvedt, Psychiatric Nurse and Family Therapist, Sørlandet Hospital, Adult Psychiatry, Mandal, Norway. Margareth.Bjortvedt@sshf.no

3. Jorunn Haga, Teacher and Family Therapist, Sørlandet Hospital, Child and Adolescent Psychiatry, Kristiansand, Norway. Jorunn.Haga@sshf.no

4. Karin E.Hildèn, Social Worker and Family Therapist, Family Services in Vest-Agder County, Kristiansand, Norway. Karin.E.Hilden@bufetat.no

Translated by:

Sigurd Reimers, Therapy Service Manager, Foster Care Associates, Bristol, UK 


\section{Abstract}

This article focuses on young abusers participating in a treatment program for families where one or more children have experienced child sexual abuse and/or have abused other children. TVERS is a multiprofessional team where the treatment is performed within a frame of control ,"care and control hand in hand". Three trained family therapists from three different agencies come together and form the therapy. The caseworker from the child care protection service (Children`s Service) becomes a part of the TVERS-team during their therapeutic work with the young abuser and his family. The therapists are given access to all reports and documents from the police, the court and medical services. The caseworker can follow up the family between appointments as well as initiate child protection procedures if necessary. The article describes our experience of working with families where the son in the family has abused other children outside or inside their own family.

\section{Introduction}

There are many types of relationships where sexual abuse occurs. Some abuse is carried out by children against other children. Suspicions of, and disclosures about, children's sexually abusive behaviour against other children, raise particular taboo-related feelings. Disbelief, denial, minimising and excuses are well known and common reactions on the part of many parents and other family members (Pipe et al 2007). A number of professionals also experience uncertainty and a lack of knowledge about this issue (e.g. Ladwa-Thomas 1999). The boundary between sexual abuse, sexual exploration and mutual sexual play make working with this group of children a challenge for the different helping agencies. Some follow the line of least resistance by claiming that the child will "grow out of it" (Green $\&$ Masson 2002), whereas others perceive the young person's behaviour as destructive for all involved, and offer the children treatment. Forms of treatment include individual-, group- and family therapy, and forms of intervention are multiple and varied (Thomas 1997, Borduin\&Schaeffer 2002, French 2004, Saunders et al 2004, Caffaro\&Conn-Caffaro 2005). Although research around prevalence rates reveals that around a third of all sexual abuse is carried out by persons under the age of consent (Finkelhor 1996, Ladwa-Thomas 1999, NRSB 2002, Vizard 2006), the phenomenon has only relatively recently received interest in many European countries, including Norway. Relatively little has been written about work with children who abuse other children sexually. There may be a number of reasons for this. One explanation can be the lack of systematic work around developing assessment- and treatment facilities for this group of children in Norway. Another can be that professionals, who have experiences in this area, do not communicate this in the literature.

In this article we will describe some experiences from the multi-agency treatment service TVERS in the county of Vest Agder in southern Norway. The term TVERS in Norwegian means Across or Crossover. We devised the term to emphasize the multi-agency aspect of the work. Ours is a service for families where a child has experienced sexual abuse and/or has carried out such abuse on other children. Our experience of work with young abusers is limited, but through the treatment of families with such problems we have developed some insights, which we wish to disseminate. In addition to these cases we have gained some insights into the behaviour of young abusers through accounts given by other children who have experienced such boundary defying actions. Another reason for publishing these experiences is our wish to encourage colleagues in a variety of settings (child and adolescent mental health services (CAMHS), child care protection services (Children's Services), ${ }^{1}$ adult psychiatry, police, schools, residential institutions and others) to share their own knowledge in this area, especially the times when they are searching to develop competence in this

\footnotetext{
1. The municipal services with statutory responsibility for child care protection
} 
field. The large number of children and adolescents who abuse sexually suggests there is a need for professionals in all child-related agencies to focus on this group of children. Sharing of experiences can be a useful contribution to encouraging and developing skills and competence in the work around investigation, assessment, protection, and treatment. In this article we will use the term 'young abuser' in order to be clear that, however much we wish to understand the context that shapes young people's behaviour, we consider it essential to emphasize that the responsibility for acts of abuse against other children, who may be physically and emotionally harmed by these acts, has to remain with the young person concerned. However, in line with commonly-held social work and family therapy values we remain cautious about labelling vulnerable individuals-however serious their actions- in a way that is oppressive and also risks preventing rather than encouraging change.

\section{Children and young people who abuse}

How can we differentiate between children's and adolescents' normal sexual development and sexual abuse? Ryan and Lane (1997) offer a definition which suggests that a young abuser is a person who carries out sexual actions against another person, irrespective of age, against the victim's wish, without consent or in an aggressive, exploitative or threatening way. In order to draw a clearer distinction between consensual and exploitative actions, Ryan and Lane claim that terms like "consent", "equal power", and "choice" can be of help in the assessment. Further that "consent" involves an understanding of the purpose and nature of what one is consenting to, as well as being aware of the consequences of these actions. It is worth noting that Ryan\&Lane (1997) do not attach much importance to the difference in age between the children, as some others do when they come to assessing and defining the sexual relationship (Kjellgren 2000). Rather, it is important to obtain concrete descriptions of the sexual behaviour in order to find out more about the children's behaviour and relationship. Children are referred to TVERS after Children's Services have interpreted and defined the sexual behaviour as abusive and not just as a natural process of exploration between peers. One example is the adolescent who touched pre-school girls on a number of occasions. The girls knew the boy and trusted him implicitly, and the age difference between them was about ten years. Birkhaug et al. (2005) refer to the study in Hordaland County, Norway, in which the most common form of reported abuse was full intercourse or attempts at intercourse or oral or anal sex. This is in line with studies in Sweden, Britain and the USA, which indicate that most sexual abuse involves physical contact, often penetration or attempts at penetration, and also that most of the young abusers involved use force or threats of force (Manocha\&Mezey 1998). There is therefore no reason to play down the importance of sexual abuse carried out by children, neither of the effects this can have for those who experience the abuse.

The conclusions from the various studies of children who abuse other children sexually do not vary substantially. Studies reveal the same tendency as studies of adult abusers. More than $90 \%$ of those who are registered by any public agency are boys or men. Usually the young abuser and the abused child know each other already. In many cases they are closely related, as for instance with siblings. Knowledge about people who act out sexually suggests that between $30-70 \%$ have themselves experienced sexual abuse. Moreover the combination of having experienced sexual abuse and other risk factors increases the danger of going on to perpetrating abuse. These other risk factors include physical abuse, neglect, poor attachments, and violence to other family members (Manocha\&Mezey 1998, Lee et al. 2002, French 2004, Vizard 2006).

Our experiences are in line with this knowledge. From our own material it can seem as if the parents of several of the boys have had mental health or social problems themselves, and these may have undermined positive attachments between parents and children. 
As mentioned in the introduction attitudes vary as to what one should call children who abuse sexually (Vizard 2006). Some researchers and practitioners feel that one should be careful about labelling children "abusers". This term appears to be stigmatizing from both a family and a societal point of view. Furthermore the use of such a general term may tempt professionals to relate to these children as a homogeneous group, and not as unique individuals. The national GRUF project in Sweden decided to draw a line at age 13. Children between 13 and 18 years of age are described as 'young abusers', whereas below that age they are referred to as `sexually acting-out` or 'sexually reactive` (Kjellgren 2000). A pilot project in Vest-Agder chose to use the term 'children and adolescents who display worrying sexual behaviour' (Søftestad 2000). The reason for this was to discourage professionals, who were uncertain about what terms to use, from not taking appropriate action when they came across children displaying worrying behaviour. It was assumed that many would hesitate using terms like "abuse" and "abuser". Young children can, however, show a behaviour which is sexually aggressive, controlling or problematic in other ways. One example is playschool children who lick other children's crotches or try to place their willy into another child's bottom, and this is why some authors choose to describe all children who display this type of behaviour as "young abusers". As the title of this article states, we find this term most appropriate. The reasoning behind this is a wish to underline that these actions are unacceptable, as well as to stress that the child in question needs help to control, stop and change their behaviour. During the therapy sessions, however, this term is not used in the presence of the boy or his parents, but the therapists do refer to such behaviour as sexual abuse in referral letters or at professionals' meetings. Our hesitation about using the term "abuser" is, as mentioned above, related to the risk of stigmatising. At the same time there is no advantage in being unclear in one's terminology. Lack of clarity can be seen as a sign of trivializing the sexual behaviour.

Norway is a society that is rapidly becoming multi-ethnic and multi-cultural, although largescale migration from abroad did not begin until the 1970s. In due course we would expect to come across a lot of different ethnic groups in TVERS, since sexually abusive behaviour is not limited to specific ethnic groups (Ryan 1997).

The young boys in our service, so far, represent a cross section of our society in all respects. Intact and re-formed families; all social groups, from academics to the unemployed; rural and urban; host and migrant communities; outwardly well-functioning and outsiders. All these are represented in the problem of sexually abusing behaviour, even though the work presented here is based on a small group of young people.

In Norway it is possible for children from the age of 15 to be punished if they have broken the law. This also applies to sexual offences. Usual practice is for the local authority Children's Services to become involved, whether or not the child is over or under 15 years, and irrespective of whether the Police and Courts are involved. Children's Services may, as one of their interventions, refer the boy for treatment. In Norway this usually involves a referral to CAMHS, where the child is offered individual therapy. In some places there are other, more customized services, such as TVERS.

\section{Young abusers in TVERS}

TVERS is different from most other family therapy services in particular ways:

- it works exclusively with families where one or more of the children has experienced sexual abuse, and/or where a child has sexually abused other children

- it is a multi-agency team, and consists of three therapists from three different agencies. The therapists come from CAMHS, adult psychiatry and the Family Treatment Centre. ${ }^{2}$

2. Firstline treatment, offices in every part of Norway 
- The families come to TVERS at the initiative of Children's Services, and they are the referring agency. The caseworker who is responsible for the case, joins the TVERS-team whilst the family treatment takes place. The therapists are given access to Children's Services reports, as well as police documents, court proceedings and medical reports. They can also follow up the family between appointments as well as initiate child protection procedures. The aim of this collaboration is to ensure that care and control go hand in hand. (Nordstoga 1998; Wulff 2000; Søftestad et al. 2006). This attitude is based on the belief that children need both to be protected against further abuse, as well as to be protected against carrying out further abuse. However, experience suggests that control and protection cannot be guaranteed, even in families where abuse has been spelled out to carers, helping agencies and the legal system.

The young abusers who have been referred to TVERS were all boys. Sexually abusive behaviour is a highly gendered problem, and it therefore comes as no surprise that the young abusers we meet are all boys. The lower representation of female offenders in all published literature may be symptomatic of an overall reticence to identify the sexual abusive behaviour of girls and women, because of the dissonance with cultural expectations (Ryan et al. 1996). Although gender does appear to be a fairly constant factor, we need to be attentive to the importance of being alert to those instances of sexual abuse carried out by young women. The study performed by Ryan et al (1996:22) provided data from 90 contributors in 30 states in U.S. on more than 1600 juveniles referred to them for specialized evaluation and/or treatment following a sexual offence. The range of age in the sample was 5-21 years, but $90 \%$ of the sexually abusive youths were between 10 and 18 years of age. $97.4 \%$ were boys and $2.6 \%$ girls. However, more than $22 \%$ of the young people in this study reported that the perpetrator of their own abuse was female.

The boys in TVERS have been between ten and eighteen years old during the treatment period. Several have been exposed to sexual abuse themselves. This means they need to be treated as sexually abused children, at the same time as being subject to therapy and supervision by Children's Services because of their abusive behaviour towards others. Moreover we have found neglect in a number of the families. In TVERS the neglect by adults has taken the form of

- a lack of understanding of the child's situation,

- confused patterns of intimacy, as well as

- a disturbed understanding and practice of maintaining appropriate boundaries between parents and children in a variety of ways.

The families in TVERS tend generally to have talked little, or to have avoided talking together about difficult subjects, for instance about parental divorce as well as the practical and emotional effects of this. Sexual behaviour has seldom or never been talked about by adults with their children. It seems as if several of the boys acquired their information about sex generally from the media and specifically from the internet, something we assume is very common for most young people. However, we believe that the consequence of having the internet or media as one's only source of information is particularly negative for young people who have a variety of problems in relation to themselves, their life circumstances and their emerging sexuality.

In a number of the families it appears that there is a history of sexual abuse against children that has repeated itself across several generations. The young abusers who have been through TVERS have not had problems with addiction. Some of them had displayed behaviour that adults associate with ADHD, but none had received such a diagnosis. 


\section{What is the aim of family therapy with young abusers?}

The treatment of abusers is not just a question of applying therapeutic techniques and methods. Just looking for explanations for the behaviour and working with individual behavioural change seems to us to be unrealistic and pointless. Work towards change has to take place within a context. Treatment therefore also involves looking at how people in the family, within the social network and in society generally view those who abuse children sexually. Generally the portrayal of people who abuse children is uniformly negative. In specific cases most people react with alarm and condemnation, or with avoidance and silence. What sorts of reactions do young abusers encounter from family, friends and neighbours? How do Children's Services approach the young abusers for whom they have responsibility? What sense do people make of the abuse? Is the behaviour a sign of childish exploration, an act to achieve intimacy or a sign of an emerging paedophile? The reactions of the environment are highly influential for the young abuser, for the children he has abused as well as for the families of both. We know of neighbourhoods which have set up neighbourhood watch-like schemes in order to prevent contact between the young abuser and children in the locality. The negative ripple effects of this are therefore one key reason why many professionals claim that it is important to address the reactions, attitudes, and opportunities for action of all the family members as part of the treatment.

The aims of family treatment in TVERS can be summarized under five headings:

- To prevent further abuse

- To help the boy and family function as individuals and as a family after disclosure of abuse

- To guide children and parents to acknowledge the seriousness of the behaviour

- To help the boy take responsibility for the abuse, possibly also involving a meeting with the victim

- To help the boy develop increased self-respect and belief in the future.

\section{What factors get in the way of achieving these aims?}

Sexual abuse against children is a phenomenon, which in the western world carries with it a cultural taboo, which, like all taboos, involves prohibiting things from being made visible or talked about (Herman 1992). Taboos are maintained by despising the person who breaks the taboo. Contempt can lead to shame, and this is something most people wish to avoid, whether they realize it or not. Most cultures maintain an incest taboo, and there is generally a strong prohibition around sex between adults and children. Sexual pressures, harassment and abuse are not officially acceptable, whatever the age, although in practice there are strong inconsistencies and ambiguities around what constitutes harassment or abuse.

Sexually aggressive or acting out behaviour between children is made the object of the same taboo-creating forces that we recognize in incestuous relationships and sexual acts between adults and children. Wherever suspicions or disclosures of child sexual abuse appear, the common responses are denial, minimising and excuses (Pipe et al 2007). This applies to both the young abuser, the rest of the family and the professionals who are involved.

If the abuse is acknowledged by the child, the parents and the rest of the family, there are often feelings of shame, contempt, guilt and stigma. Silence is therefore a common survival mechanism, in the sense that what is not talked about, does not exist (Fürniss 1991). Additionally, professionals need to be aware that the parents' anger and feelings of powerlessness can lead to the boy being punished, physically or emotionally abused, or threatened with abuse.

Our experiences in TVERS are in line with the points outlined above. Sexual abuse awakens strong feelings. It is not unusual that parents experience a variety of emotional reactions, such as: "The mother of the abused child must have misunderstood what happened!" 
"I'll never dare look my neighbours in the eye again." "Is our son a paedophile?" "Now he can really face the music! We'll guard every step he takes 24/7!" "Have we made some mistakes in the way we're bringing him up?" "Did this happen because of our arguments and marital problems?" It is not unusual that the family experiences fear: fear about the boy's future, for his sexual development and behaviour, and about who will come to hear about the abuse. If the parents express such reactions, this need not get in the way of family treatment. On the contrary, reactions such as shame, contempt, fear, and anger can be a crucial starting point for work with the family.

It is a different matter, though, if the parents are strongly opposed to acknowledging the seriousness of the behaviour that has been exposed. They may be sceptical about the abused child who has talked about the abuse, about those who passed the information on, as well as about how their son's behaviour is to be made sense of and understood. It is not unusual that they play down the matter and have unrealistic hopes that the abused children will never mention their experiences to other children, neighbours, or at school. If work with the parents' own resistance is not successful, and this resistance persists, it will get in the way of an acknowledgement of the situation in which the child and the family find themselves. Work towards change, which is essential to prevent further abuse being carried out, becomes more difficult.

The young abuser is often without words and full of shame. Where parental denial is combined with the young abuser's silence, the therapists face a huge challenge, particularly as the parents' attitude gives their child "permission" not to talk about what he has been doing, thinking and feeling. In such circumstances the boy will be able to choose the same strategy and thereby reduce the possibility for addressing his experiences and help him tackle future challenges.

Obstacles can also occur in the form of complications outside the family. As we have mentioned, the caseworker from Children's Services takes part in the TVERS project. The caseworker's understanding of what has happened, and attitude to how the child and parents should be approached, is crucial when it comes to treatment. The process around the therapy sessions might lead to the caseworker changing his or her mind and consider the child's behaviour as age appropriate sexual exploration. If the therapists, however, believe that the behaviour is aggressive, intrusive and worrying, there is a real danger that treatment will terminate. Another possibility is that conflicts develop around the aims of continuing with therapy. An example of this is where the parents and Children's Services wish to work at education around normal sexuality, whilst the therapists prefer to focus on creating change in the abusive behaviour. Our experience, therefore, suggests that more often than not a positive outcome is linked to the presence of Children's Services in the treatment process.

\section{What helps in achieving the goals?}

TVERS seeks to address the obstacles mentioned above in a number of ways. Our practice has developed through years of experience in treating families where children have been exposed to sexual abuse.

First of all, the therapists, as mentioned previously, have access to detailed descriptions of the sexual behaviour via Children's Services records, as well as any reports from school, police or others who know the child. They are in other words not solely dependent on the young abuser's own accounts. The basis for the referral is the information about worrying sexual behaviour. The main focus of treatment is agreed between Children's Services, the family and the therapists in TVERS before the work commences. The information that has been gathered becomes the basis of an account of a particular reality, and this is what family members and Children's Services then have to relate to in one way or another. 
Secondly, the therapists stress the importance of using a direct and respectful language and to find concepts that the child, parents, and therapists can use in their conversations about sexuality and abuse. The language used creates an agreement that it is acceptable to talk about sexuality generally, and specifically about sexual feelings and actions. The therapists' own comfort in working within the field of sexual abuse, as well as a sense of security and trust with each other, provides an atmosphere of openness around a theme which in most circumstances and relationships is full of silence and insecurity.

Another point is that a security that comes from long experience also permits one a freedom to follow the family's pace without foisting themes on the family that seem to be demanded by professional conventions. The therapists aim to show attentiveness and sensitivity as to the timing and context for bringing up various themes. In this process we make it a priority to look after each family member. That is to say, a sense of care which involves understanding without condemnation.

The TVERS therapists' work with families where children have suffered abuse does not differ much from that carried out with the families of children who have abused other children. However, certain aspects of the work with young abusers are different. One aspect is that we emphasize more the importance of building a good relationship between the therapists and the parents before the child joins the sessions, as we will see in the next section.

\section{Description of the work of TVERS}

Contact and "contract-making" with the parents

The most important phase in the work is the establishment of a relationship. This primarily involves the first contact and making a "contract" with the parents, which is going to form the foundation for work with the boy. The main aim of this is to support the parents, or even enable them, to be a resource for their son, both in therapy, in their day-to-day life, and in the future. The meetings between the parents, Children's Services and the therapists have several subsidiary goals:

The first step is to get to know the parents, in order to obtain information about them, about their children and about their experience of the situation they have found themselves in. In this phase new and crucial information may come up, about circumstances that the parents have not talked about before either with each other or with outsiders. One example was the man who, after many years of marriage, heard about his wife's own experience of abuse as a child for the very first time. Also, in most cases the representative from Children's Services has not got to know the parents before treatment starts. In those families where the parents themselves have had a difficult childhood and have a great need to talk about their own experiences and problems, it is an advantage if this can be discovered early in the phase where the relationship is being established. Experience suggests that situations can arise where the therapists need consciously to maintain a balance between a focus on the parents and a focus on the young abuser. Where the parents' background is given too much attention, this can set off emotional reactions which can create anxiety and frustration, and this can be an obstacle to the boy's therapy rather than act as a resource.

Another aim is to have spelt out the parents' knowledge and their attitude to the available information about their son's sexual behaviour. Have they been adequately informed? Do they believe the information is correct? How do they understand and interpret what they have heard? How have they related to their son after having heard about the abuse? A third aim is to examine and discuss any circumstances, which may have consequences for the boy, both in his day-to-day life and in the treatment. There may be issues relating to the couple's own relationship, their joint parenting and their relationship with their local 
network. What effects do the revelations about the boy's sexual acting out have on the couple's relationship? Do they blame or support each other? Do the parents relate differently to the boy in this situation? What exactly are they going to tell the rest of the family and their network?

The "contract" between the parents, Children's Services and the therapists can be particularly challenging when the parents are divorced. It is apparent that some divorced parents are less united than they should be in taking responsibility for the child getting into the situation in question. Some try and pin the fault and responsibility for the abusive behaviour onto circumstances relating to the other party and/or their family. If it has been discovered earlier that there has been sexual abuse in the family of one of the parents, this may give the other parent an opportunity to blame their ex in-laws for being the "cause" of the boy's abuse. Such conflicts are addressed during the treatment. The aim then is to make clear how disagreements and blame can influence the work with the boy and his problems, and to try and find some resolution of this before the boy is involved in the treatment.

The fourth aim of the meetings before meeting the boy is to supervise and prepare the parents for how to relate to and care for the boy after and between the therapy sessions. Parents may need help seeing the situation from their son's perspective, in seeing other sides to him, and help in achieving a better balance between care and control. Ought they to comfort him and show that they feel sorry for him? Should they guard him 24 hours a day? Where it is appropriate and desirable, the Children's Services representative can follow up on these points, by for instance being available to the parents on the telephone for discussing specific day-to-day situations that may crop up.

An equally important aim is to offer the parents an opportunity to talk freely about their own reactions to their son's sexual behaviour: for instance shame, guilt, anger, powerlessness as well as fear for the future. One example is the father who expressed great concern that his son might be a paedophile. This became a theme for discussion between the therapists, Children's Services and the parents, before the work with the whole family commenced.

Experience indicates that the outcome of this first contact with the parents is of decisive importance when it comes to outcome of the boy's treatment. The parents' role in motivating the boy towards treatment in the first place is crucial. It is unlikely that young abusers will approach treatment of their own accord without been coaxed or forced by their parents, Children's Services or the police. Secondly, as we have previously mentioned, the attitude and reactions of the parents are important for the outcome of the treatment process itself. However, family therapy offers a good opportunity for bringing into the open any resistance, conflicts or other obstacles, so that these can be addressed in detail and collaboratively, both at the meetings with the parents, and where relevant also in the individual sessions.

\section{Adjusting the method to fit the family}

The type of work, methods and theoretical foundation of the TVERS therapists has been described in an earlier article (Søftestad et al. 2006). Basically the work uses an eclectic approach, with systemic therapy forming the foundation. Additionally we use other therapeutic approaches, adjusted to the needs of each child and each family, as these emerge during the therapy process. We draw on methods from play therapy, environmental and narrative therapy, to mention just a few. Flexibility and diversity in the use of methods is possible because the three therapists have a varied basic training, a variety of further training, as well as clinical experience in different settings over many years. In addition, the therapists have worked together over a long period, so that they feel safe in relation to each other's competence. 
At the first joint meeting between TVERS and the family, Children's Services hand over all the information relating to the case. They explain the whole process, from when they first received the child protection referral until the referral to TVERS. As mentioned above, this information includes everything Children's Services has already shared with the team, and all that they themselves have so far done in relation to the case. The history behind the abuse is described, and different people's accounts about what they had seen and heard are also detailed. This is often the first time the abuse is plainly spelled out to the whole family. This openness and the direct and respectful language provide a useful pattern for future interviews.

Family members are asked to give their own views and reactions. In this way both therapists and Children's Services become familiar with how each person relates to the situation and how the family as a whole is functioning at the time treatment commences. The accounts are followed up with questions from the therapists and reflections between them, in order to assess whether the boy himself is experiencing sexual abuse, whether he has carried out further abuse beyond what has already been disclosed, and generally whether there are other types of harm and abuse taking place that have not yet been disclosed. Our experience suggests that the greatest challenge is to get the child or young person to talk about himself, his experiences and his understanding of the abuse as well as the situation in which he now finds himself.

In order to help the boy identify what is going on both inside and outside himself before, during and after the episodes of abuse, we use a so-called "cycle of abuse" or "addictive cycle". In this part of the work we use aspects from cognitive behaviour therapy. Fürniss (1991) describes one type of "addictive cycle" (see Fig.1) which contains six different phases, namely tension, fantasy, planning, arousal, abuse and relief. The circle shows how the abusive behaviour consists of a chain of feelings, thoughts, choices and events, which follow each other. Through the work with this cycle the boy can learn more about himself and his behaviour, as well as learn more about what specifically he can do to break this pattern and thereby prevent further abuse from taking place.

\section{Fig. 1 "The addiction circle" in here - see the attachment)}

Having focused on the first time the abuse occurred, we move to questions about the second and third occasions and so on. The questions need to be as specific as possible: "What happened?" "What did you feel before it happened, and whilst it was going on?" "How did the abused child react?" "What did the child say or do?" "How did you feel afterwards?" In this way, it can become clear to both the child and the therapist what had triggered the process and where he had lost control and then carried out the abuse. It appears that once the barrier against using force to achieve sexual satisfaction has been broken on one occasion, the barrier against repeating the abuse again and again then becomes weaker and weaker.

One important part in the treatment process is encouraging the young person to acknowledge his responsibility for the abuse which has occurred. Some find it hard admitting that they have carried out the abuse, which the abused children have talked about. Others admit what they have done as soon as they have been confronted. One example is the boy, who immediately confessed to the abuse when the parents asked him directly. Moreover he shocked them by telling them about other abusive incidents with other children.

Admitting and taking responsibility for abuse can be a long process. We therefore work with child's ability to show empathy, that is, a capacity to put oneself in another person's place. The child is challenged to see the abusive incidents from the abused child's perspective. What was it like being the abused child in this situation? TVERS has some experience of boys who have gone on to meet the children they have abused, in order to apologize for the wrong and harm they have done to them. One boy aged 12-13 asked a girl, who lived 
nearby and was younger than him, for forgiveness for the sexual abuse he had done to her. When he had first come to TVERS, he had described his actions as play, whilst the girl had experienced them as abusive. When he later apologized, the girl brightened up, and explained clearly that she was relieved and glad to hear this.

We work hard at making sure that the young people receive ordinary sex education. As mentioned before, sexual development is often a theme avoided by families, and the child has therefore acquired his knowledge by a variety of means. Many do not have the basic knowledge about the body (both their own and that of the opposite gender), sexual feelings and behaviour. Such gaps are sometimes covered over, as when the child uses well-known terms in the sessions. But through direct questions, it can turn out that the child has a missing or mistaken understanding of what these terms refer to and mean. Whether this education takes place in the individual sessions with the child or jointly with the family, can vary from case to case, depending partly on the child's age. Adolescents tend to a greater degree than younger children to talk about sexual development without their parents present. The therapists may also choose to help the carers in talking about sex with the child. One example is the stepfather who was helped to guide his wife's son. The boy constantly had an erect penis, and this made it difficult for him to pass water. The stepfather became the boy's guide in the various everyday "mail" situations which cropped up.

Incest between siblings has also been a theme in TVERS. These cases seldom end up in the public eye and many professionals play down the seriousness of sibling abuse (Caffaro\&ConnCaffaro 2005). Questions about where the boundary between mutual exploration and sexual abuse goes, are put to the test. Information suggesting that one of the children has forced a sibling to participate in sexual activities against its wishes, puts parents in a particularly difficult situation. Setting limits, control and the risk of further abuse are particularly challenging because the children share the same house. The role of Children's Services in relation to assessing risk, control and protection, whether this concerns being abused or carrying out abuse, become crucial issues. The caseworker needs continuously to assess whether the children's care environment and the parents' ability to provide control are satisfactory. One family from TVERS shows how a father's clear acknowledgement of the situation had a decisive effect on the treatment. The father clearly distanced himself from his son's abusive behaviour. He showed that he could understand his daughter, who had been abused. In a constructive way he used his authority by restraining his son when the son stood up in order to leave the therapy room: "This is serious. All three of us need to talk about this."

\section{The therapists as a resource}

Therapists naturally face a number of challenges in their work with children and adolescents who have experienced sexual abuse or who have themselves abused others. These challenges relate to theory, clinical skills, and to their own emotional reactions (Thomas 1997). Both the themes raised and the style of treatment can lead to a closeness to the family members which can "erase" the original roles of therapist ad client. When therapists become aware of this, the closeness can be used in a positive way. By "stepping out of", or distancing oneself from the structured role as therapist, one can employ a more personal style. The aim of this is to create relationships that are appropriate to the treatment context, cf. Ryen and Silverman (2006).

However, a close relationship with the clients can also have another side. Therapists in TVERS have experienced that their work can led to strong feelings of injustice, sadness, anger and hopelessness. Such reactions can contribute to professionals themselves experiencing secondary trauma when they are closely involved with traumatized clients (Pearlman and Saakvitne 1995; Blanchard\&Jones 1997). 
In order to function as a good therapist, it is crucial that they have a high degree of competence, considerable experience and security within this field. One skill that stands out as being particularly important is the ability to be able to relate to children and adults, including an ability to communicate with them around themes that are difficult and taboo. Moreover, a relationship of trust with colleagues and an ability to establish good collaborative relationships are also important. Work with people who have been abused or who carry out abuse should not be carried out on one's own. Rather, it is strengthened when those involved recognize each other's work and in different ways contribute to each other's wellbeing. In addition, each therapist's personal attitudes and characteristics are relevant, for instance an ability to live close to a child's pain, to tolerate people's darker side, as well as to be patient in a change process that is going to be time consuming. TVERS therapists have found, as have other professionals in similar work settings, that a sense of humour can be a strength when one is working close to traumas and tragedies. The balance between being serious and seeing the lighter sides of life is stressed by a number of people (Schauben\&Frazier 1995, Blanchard\&Jones 1997).

As we have already mentioned, the therapists in TVERS come from three different therapeutic agencies. Working together as a team makes the treatment package less precarious. If one of the therapists is unable to turn up for a particular session, one of the others can carry out the interview without having to cancel. Secondly, the families can enjoy the benefit of a balance and breadth of treatment by not having to be dependent on the competence of only one therapist. The presence of three therapists in the same room leads to a refinement and thoroughness, both when it comes to knowledge and to clinical skills. Thirdly, this collaboration offers an opportunity for internal debriefing and facing one's own "blind spots". The pain involved in meeting people who have experienced sexual abuse or who have perpetrated abuse, can in some cases be so great that even experienced therapists may start minimizing, for instance by making the abuse seem less serious or by reducing the focus on the reactions of the family members. Involvement with, and pity and sympathy for, the young person can make it hard to relate to his negative behaviour. Therapists can be tempted into having thoughts such as "this probably only happened once" or "he'll grow out of this". A feeling of security within the TVERS team has made it possible to point out these tendencies to each other where these have cropped up.

\section{Does TVERS work?}

So far the treatment has only been evaluated by the therapists themselves, in addition to feedback from Children's Services and family members themselves. However, we would like to make following points:

Duration of treatment is approximately ten sessions over a period of 6 to 9 months. In most cases the treatment is concluded earlier than the therapists wish. Usually the families wish to finish as soon as humanly possible. The discomfort of dwelling on abuse that has been disclosed, and the need to "live normally again", often lie at the heart of such a wish. Young people who reach 18 during the process, may use their right to conclude the therapy once they have reached the age of consent, and this usually corresponds with the parents' wish as well. During the period the family is working with TVERS there is usually continual contact between therapists, Children's Services and the family in order to motivate and retain them in therapy. The reason for this is that the therapists may discover a number of relationships which one could with benefit be worked with. Even if the treatment finishes before this has been achieved, the process may still have had a positive impact on the boy and on his family. Many of the families have achieved several of the desired aims of treatment: Family members have had an opportunity to show their reactions to the situation they find themselves in. Parents have received guidance in how to help their child. The child has 
received clear signs that the abusive behaviour is unacceptable, and that it is possible to receive help in order to stop.

Helping the family to break the silence which is a well known feature of sexual abuse is, as we have said earlier, our central goal. Our experience is that a number of parents avoid or actively oppose involving the young abuser's siblings. The TVERS therapists' basic position is that a large part of the social network, for instance siblings, grand parents or other people who are important to the child, can usefully be informed and become involved. This needs of course to be assessed in each case, depending on each family's context, for instance whether other family members have the capacity and opportunities to be a positive resource or not. However, siblings are in a particularly important position, and may live with unspoken issues and feelings of shame. They may also be exposed to their brother's abuse and become involved with him in abusing others. The pressure to keep the abuse silent can understandably be great, which is why it is a particular challenge for the therapists to pose the question about information to third parties. The aim of this is that questions about involving siblings or relevant other people should be an object of discussion between therapists, parents, Children's Services, and the young abuser.

We also need to consider that a process that has commenced and then prematurely terminated can have a negative effect. Serious themes and emotional reactions have been opened up, but the process of therapy, follow up and guidance has been broken. There is then a real danger that new wounds and conflicts between family members will develop, for instance through strong mutual blame, inappropriate punishment of the child or social isolation by the family brought about by a feeling of shame.

A planned termination is the best termination. In the concluding phase it is usual to summarize the themes that have been addressed in treatment. Going through the process of therapy can make visible the process of change both to the child, the parents and Children's Services. Another theme in the concluding phase is to spell out any plans that have been made, or that need to be made, in order that the child can be adequately cared for in the future. The best way of concluding is when the child and his parents can finish with TVERS with hope for the future, in the belief that they can tackle difficult situations, and with a better self-image at the end than when they started.

The longer term effects of the TVERS treatment are not known. A general evaluation as well as research on long-time effects including interviews of all the participants; boys, parents, child care protection workers and therapists, could give interesting and new insights into whether family treatment can contribute to the work of helping abusive children and their families, and of preventing further sexual abuse.

\section{Conclusion}

This has been a description of a multi-agency treatment project whose aims have been to provide treatment for young people who display sexually harmful behaviour. We have particularly emphasized the importance of involving the whole family in order to shore up changes in the behaviour of the young person concerned. Motivation on the part of all members in addressing crucial issues of power is always an issue in working with families, not least where one member has behaved in a visibly harmful manner that also exposes the whole family to the risk of blame, embarrassment and isolation.

Although the multi-agency nature of our project has been an essential feature in promoting this motivation, statutory powers do not by themselves guarantee change. We are left with an abiding sense that we have yet to find a way to ensure that our therapeutic interventions are followed up in the longer term in a way that is effective without being intrusive. 


\section{References}

Birkhaug, P. et al. (2005) Unge overgripere: En kartleggingsundersøkelse i Hordaland. Tidsskrift for Norsk Psykologforening, 42: 978-993

Blanchard, E.A.\& Jones, M.(1997): Care of Clinicans Doing Trauma Work. In: M. Harris (ed): Sexual Abuse in the Lives of Women Diagnosed with Serious Mental IIIness, Harwood Academic Publishers

Borduin, C.M.\& Schaeffer, C.M. (2002): Multisystemic treatment of juvenile sexual offenders: A progress report. Journal of Psychology and Human Sexuality, 13: 25-42

Caffaro, J.V. \& Conn-Caffaro, A. (2005): Treating sibling abuse families. Aggression and Violent Behaviour, vol 10, 5: 604-623

Finkelhor, D. (1996): Keynote address. Presented at the International Congress on Child Abuse and Neglect, Dublin, Ireland in August 1996.

French, L. (2004): Assessment and treatment strategies for children with sexually abusive behaviours: A review of cognitive, development and outcome considerations. In: Calder, M.C. (ed): Children and young people who sexually abuse: New theory, research and practice developments, pp 134-142, Lyme Regis: Russell House Publishing

Fürniss, Tilman (1991): The multiprofessional handbook of child sexual abuse - integrated management, therapy and legal intervention. London: Routledge

Green,L.\&Masson,H. (2002): Adolescents who sexually abuse and residential accommodation: Issues of risk and vulnerability. British Journal of Social Work, 32: 149-168

Herman, J.L. (1992): Trauma and Recovery. From Domestic Abuse to Political Terror, London: Pandora, River Oram Press.

Kjellgren, C. (2000): Ungdomar som förgriper seg sexuelt. In: Mossige, S. (ed): Personer som begår seksuelle overgrep mot barn. Forståelse, behandling og straff. Kunnskapsstatus og erfaringer fra de nordiske landene. TemaNord 2000:547, Nordisk Ministerråd, København, Denmark.

Ladwa-Thomas,U.\& Sanders,R. (1999): Juvenile Sex Abusers: Perceptions of Social Work Practioners. Child Abuse Review, vol.8:55-62

Lee, J.K.P., Jackson, H.J., Pattison, P. \& Ward, T. (2002): Developmental risks factors for sexual offending. Child Abuse and Neglect, 26: 73-92

Manocha, K.F. \& Mezey, G. (1998): British adolecents who sexually abuse: a descriptive study. Journal of Forensic Psychiatry, vol 9, 3: 588-608

Nordstoga, S. (1998): Bedre samspill mellom kontroll og behandling. Embla,2:24-33

NRSB-Nasjonalt Ressurssenter for seksuelt misbrukte barn (2002): Seksuelle overgrep mot barn- utvalgte temaer, NRSB, Oslo

Pearlman, L.A. \& Saakvitne, K.W. (1995): Treating therapists with vicarious and secondary traumatic stress disorders. In: C.R. Figley (ed.): Compassion Fatigue: Coping with Secondary Traumatic Stress Disorders in those who treat the traumatized, Brunner/Mazel, pp.150-177. 
Pipe, M-E., Lamb, M.E, Orbach, Y. and Cederborg, A-C. (ed.) (2007): Child Sexual Abuse. Disclosure, Delay and Denial. New Jersey, London: LEA Publishers

Ryan, G., Miyoshi, T.J., Metzner, J.L., Krugman, R.D. and Fryer, G.E. (1996): Trends in a National Sample of Sexually Abusive Youths, Journal of Am. Acad. Child Adolescent Psychiatry, 35:1, 1996

Ryen, A.\& Silverman, D. (2000): Marketing Boundaries: Culture as Category Work. Qualitative Inquiry, Sage, vol 6, 1:107-128

Ryan, G.(1997): Sexually Abusive Youth. Defining population. In: Ryan, G.\& Lane,S.(eds.): Juvenile Sexual Offending. Causes, Consequences, and Correction. San Francisco: Jossey-Bass

Saunders, B.E., Berlinger, L. \& Hanson, R.F. (eds.) (2004): Child Physical and Sexual Abuse: Guidelines for Treatment (revised report: April 26, 2004). Charleston, SC: National Crime Victims Research and treatment Center.

Schauben, L. J.\& Frazier, P.A.(1995): Vicarious Trauma - The effect on Female Counselors of Working with Sexual Violence Survivors. Psychology of Women Quarterly, 19: 46-64

Søftestad, S. (2000) Pilotprosjektet "Barn og unge med bekymringsfull seksuell atferd". Et tverretatlig samarbeidsprosjekt i Vest-Agder. In: Mossige, S. (ed): Personer som begår seksuelle overgrep mot barn. Forståelse, behandling og straff. Kunnskapsstatus og erfaringer fra de nordiske landene. TemaNord 2000:547. Nordisk Ministerråd, København, Denmark.

Søftestad, S., Bjørtvedt, M., Haga, J., Hildèn, K.(2006): Terapi i en barnevernkontekst. Tverretatlig behandling av familier med seksuelle overgrep mot barn. Fokus på familien, 4:277-292

Thomas, J. (1997): The family in treatment. In: Ryan, G.\&Lane, S.(eds.): Juvinile Sexual Offending. Causes, Consequences, and Correction. San Francisco: Jossey-Bass.

Vizard, E. (2006): Sexually Abusive Behaviour by Children and Adolescents. Child and Adolescent Mental Health, vol 11, 1: 2-8

Wulff, C. (2000): Behandling av incestutsatte familier. Erfaring med Tilman Fürniss` terapimodell. Tidsskrift for Norsk Psykologforening, 37:915-922 